\title{
PERFORMANCE TESTING OF TENNIS AND SQUASH PLAYERS
}

\author{
S. PYKE, Ph.D., C. ELLIOTT, M.Ed., and E. PYKE, B.Ed.
}

Department of Physical Education, University of Western Australia

Tennis and squash coaches usually feel, rightly or wrongly, that their competence lies in being able to attend to three aspects of the game; skill, strategy and psychological preparation. Those labelled with the responsibility of preparing top-class teams often look to advice from the physical educator to measure and develop the other important components; stamina, speed and strength.

It is the purpose of this paper to describe batteries of tests that have been used successfully to measure the stamina, speed and strength of top-class tennis and squash players in Western Australia. Coaches can then prescribe individualized training programmes based on diagnoses obtained from these test results.

\section{Subjects}

The subjects who completed the tennis performance test battery were junior and senior members of the Western Australia tennis squad vying for positions in the teams to contest the Linton and Wilson Cups and the different State open championships throughout Australia.

The subjects who undertook the squash performance test battery were senior members of the Western Australian mens' squash squad competing for places in the team to represent the State in the Australian championships. I.

The characteristics of these players are given in Table

\section{Rationale and Description of Tests}

\section{Tennis Performance Test Battery}

The components of the tennis performance test battery are as follows:
(a) physical characteristics - height, weight, body fat
(b) stamina - $\mathrm{PWC}_{170}$ test on bicycle ergometer
(c) speed - tennis speed test
(d) strength - shoulder extension and elbow extension strength

(a) Physical Characteristics
Height was measured in centimetres by using a $\mathbb{\infty}^{2}$ stadiometer and weight was measured in $\overrightarrow{0}$ kilograms with scales accurate to $\pm 10 \mathrm{gms}$.

Table I

\section{Characteristics of Subjects}

\begin{tabular}{|c|c|c|c|c|}
\hline & $\begin{array}{l}\text { Age } \\
\text { yrs }\end{array}$ & $\begin{array}{l}\text { Height } \\
\text { cms }\end{array}$ & $\begin{array}{l}\text { Weight } \\
\text { kgs }\end{array}$ & $\begin{array}{l}\text { Percent } \\
\text { body fat* }\end{array}$ \\
\hline \multicolumn{5}{|l|}{ Tennis Players } \\
\hline $\begin{array}{l}\text { Junior Girls } \\
(\mathrm{N}=7)\end{array}$ & 15.4 & $\begin{array}{l}166.7 \\
\pm 4.72\end{array}$ & $\begin{array}{l}52.7 \\
\pm 4.93\end{array}$ & $\begin{array}{l}16.5 \\
\pm 1.66\end{array}$ \\
\hline $\begin{array}{l}\text { Junior Boys } \\
(N=5)\end{array}$ & 16.2 & $\begin{array}{l}174.7 \\
\pm 1.40\end{array}$ & $\begin{array}{l}64.3 \\
\pm 6.47\end{array}$ & $\begin{array}{l}10.4 \\
\pm 1.18\end{array}$ \\
\hline $\begin{array}{l}\text { Senior Women } \\
(N=6)\end{array}$ & 21.3 & $\begin{array}{l}163.1 \\
\pm 4.46\end{array}$ & $\begin{array}{l}60.9 \\
\pm 8.03\end{array}$ & $\begin{array}{l}18.1 \\
\pm 2.31\end{array}$ \\
\hline \multicolumn{5}{|l|}{ Squash Players } \\
\hline $\begin{array}{l}\text { Senior Men } \\
(N=15)\end{array}$ & 25.6 & $\begin{array}{l}177.1 \\
\pm 5.86\end{array}$ & $\begin{array}{l}76.8 \\
\pm 9.00\end{array}$ & $\begin{array}{l}12.0 \\
\pm 2.03\end{array}$ \\
\hline \multicolumn{5}{|c|}{ Values are Means \pm S.D. } \\
\hline
\end{tabular}

Body fat was measured because, in excess, it must be regarded as dead weight and detrimental to both speed of movement around the court and to ability to endure a long, hard match.

Body fat for males was determined by using the of regression formula developed by Yuhasz (1962).

$\%$ fat $=5.783+(0.153 \times$ sum 4 skinfold measures $)$

Each of the skinfold measurements was obtained by placing Harpenden calipers around $\Phi_{\mathbb{N}}$ and at right angles to the raised skin fold as shown in Figure 1. Measurements in millimeters were made at the following sites on the right hand side of the body:

i. triceps (arm) - half way between the acromion process of the shoulder joint 
and the olecranon process in the elbow joint;

ii. subscapular (back) - parallel to the vertebral border of the scapula and adjacent to its inferior angle;

iii. suprailiac (hip) - above the crest of the ilium and following the natural diagonal line;

iv. mid-abdominal (abdomen) - immediately to the right of the umbilicus and parallel to the long axis of the body.

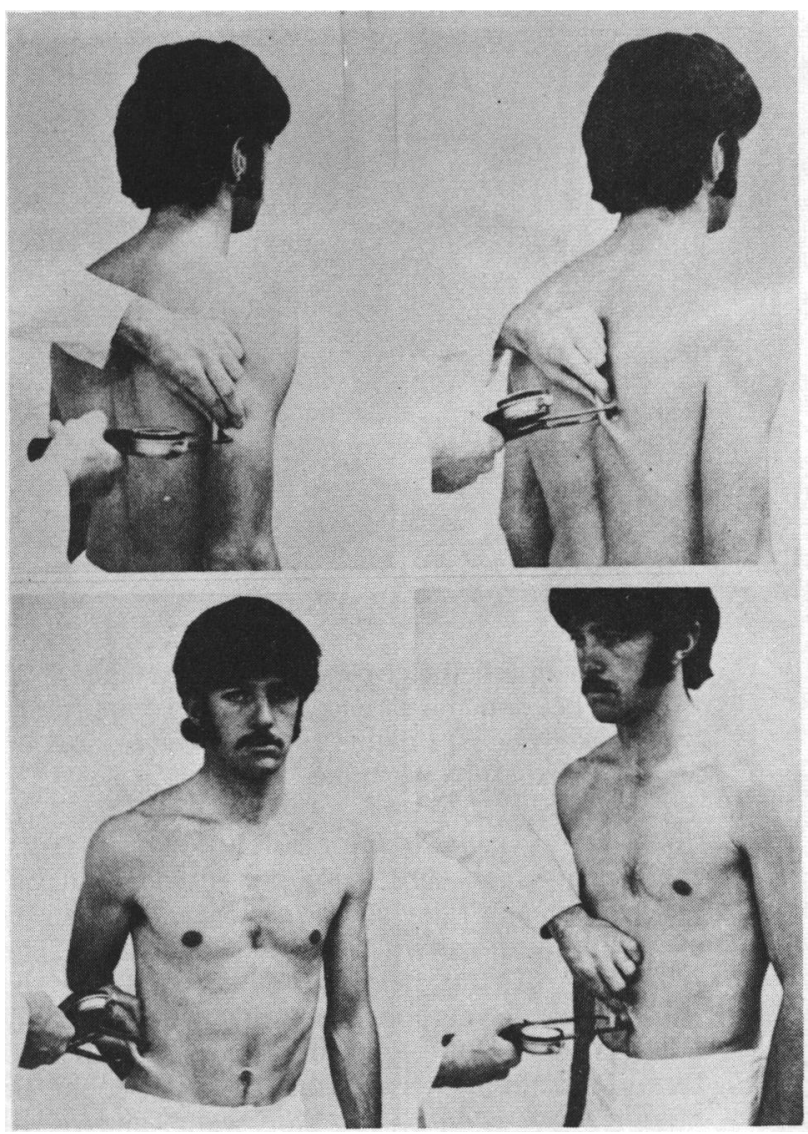

Fig. 1 Skinfold sites for triceps, sub scapular supra-iliac and midabdominal measures

Body fat for females was determined by using the regression formula developed by Sloan et al (1962):

body density $=1.0764-.00081$ (supra iliac fold)

-.00088 (triceps fold)
Knowing body density, the equation of Keys and Brozek (1953) was used to calculate percent body fat:

$\%$ fat $=\left(\frac{4.201}{\text { body density }}-3.813\right) 100$

\section{(b) Stamina}

Cardiovascular fitness becomes important in a tennis match characterised by long rallies or in a tournament spread over several days. The most widely accepted and valid measure of cardiovascular fitness is the test of maximal oxygen consumption involving collection of samples of expired air during an exhausting run on the treadmill. Even though the facilities for this procedure were available, it was considered too costly and time-consuming to warrant inclusion in a test battery designed for wide adoption. Hence the $\mathrm{PWC}_{170}$ test (physical work capacity at a heart rate of 170 beats/minute) originally developed by Sjostrand (1947) and modified by the Canadian Association for Health, Physical Education and Recreation (1968), was selected. This test required the subject to work continuously for a total of twelve minutes on a Monark bicycle ergometer, while pedalling at a rate of 60 revolutions per minute and having the resistance increased by $180 \mathrm{kgm} / \mathrm{min}$ at the end of each four minute segment. The heart rate was recorded on an electrocardiogram and averaged for the last two minutes of each work segment. The appropriate work loads for each subject were selected on the basis of stethoscope determinations made during a pre-test familiarisation session. The first work load was chosen to elicit a heart rate of between 120 and 130 beats/minute. This would generally result in an increase in rate to between 160 and 170 beats/minute at the conclusion of the twelve minute test period.

Heart rate and work load were then plotted to form a regression line by the method of least squares. This line was either extrapolated or interpolated to a frequency of 170 beats/minute. The physical work capacity was initially measured in $\mathrm{kgm} / \mathrm{min}$ and then converted to $\mathrm{kgm} / \mathrm{kg} \cdot \mathrm{min}$. upon dividing by the subject's body weight. This latter index offered the best means of comparing individuals differing in body size who are planning to perform in an activity that requires them to support and move their own body weight.

(c) Speed

The ability to return balls from all parts of the 

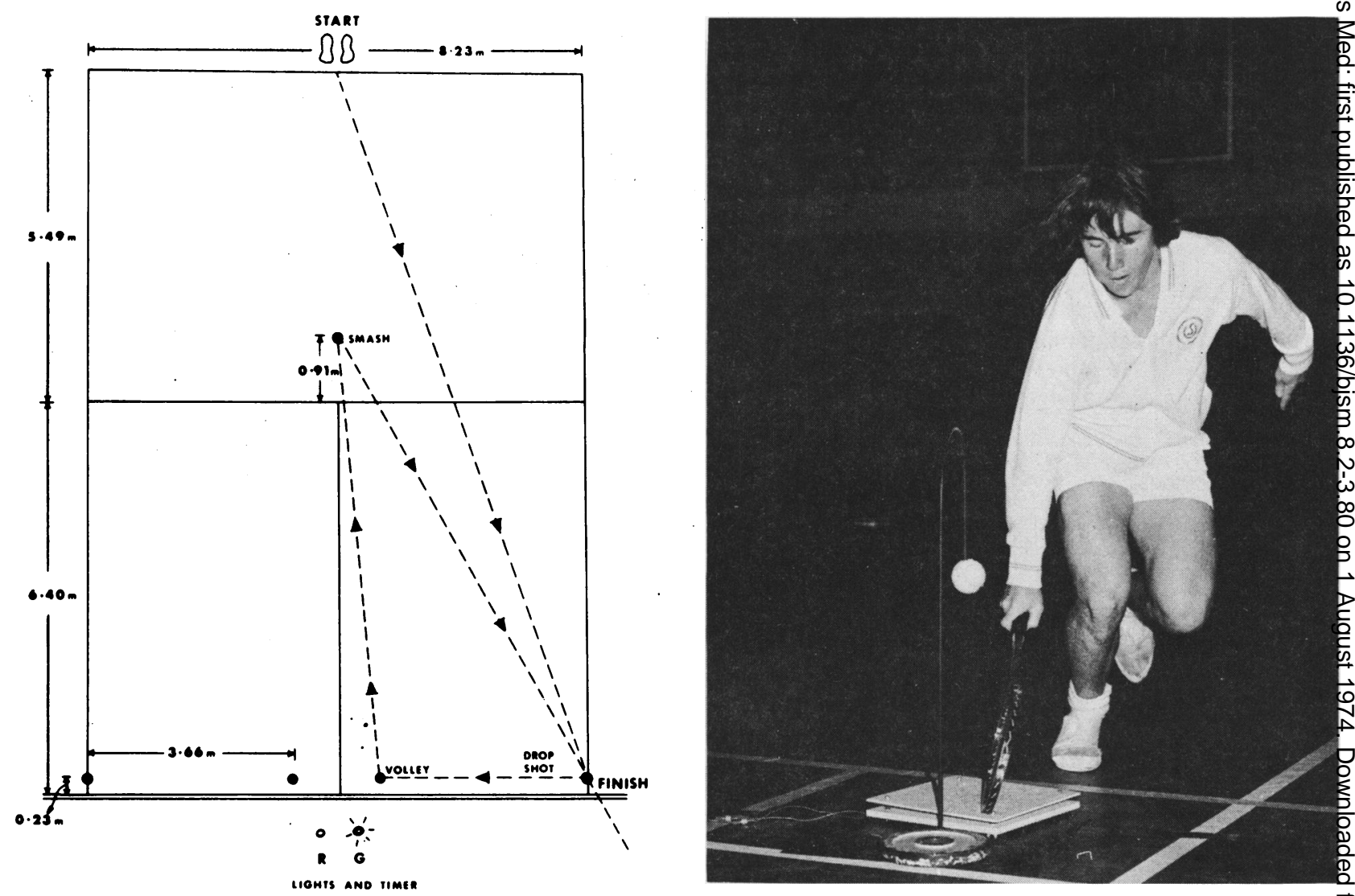

Fig. 2 Tennis speed test - dimensions and demonstration of finish position

court is dependent on speed of movement. It was considered that an agility speed run over a commonly used pattern on a tennis court provided more pertinent information than time for a short dash or a shuttle run.

The tennis speed test was conducted on a gymnasium floor marked according to the dimensions of a singles tennis court. These dimensions are given in Figure 2. The subject was timed to run the pattern while touching the racquet on a series of stationary balls mounted on stands placed at selected points on the court.

The subject commenced the test standing on the baseline awaiting the starting signal which activated a digital timer. The signal appeared in the form of either a green or a red light placed just above the net. This dictated whether a left or right court pattern was run. As shown in Figure 2, the right hander on a left court pattern runs from the baseline to the left front court sideline to shadow a drop shot (height $.48 \mathrm{~m}$ ), then to centre court at the net to volley (height $1.38 \mathrm{~m}$ ) followed by a retreat to smash (height men $2.40 \mathrm{~m}$, women $2.30 \mathrm{p}$ $\mathrm{m})$ just beyond the service line and a final returns to left front court sideline to touch the racquet on a switch that stops the timer.

Each player was given a series of six test trials the red or green light being presented in random order. Left and right court speed was assessed by averaging the best two times for each pattern. The reliability of this test, as determined by the intra-class correlation method described by Baumgartner (1969), was .98. In less sophisticateof testing situations, adequate measures could be obtained by using only a stop watch and verbaR commands.

(d) Strength

The ability to hit the explosive smash or passing shot is somewhat dependent on the strength of the muscles involved in the stroke. Even though it is considered that a certain amount of muscles strength is necessary to do this, it is not known precisely how much. Hence these tests were only 


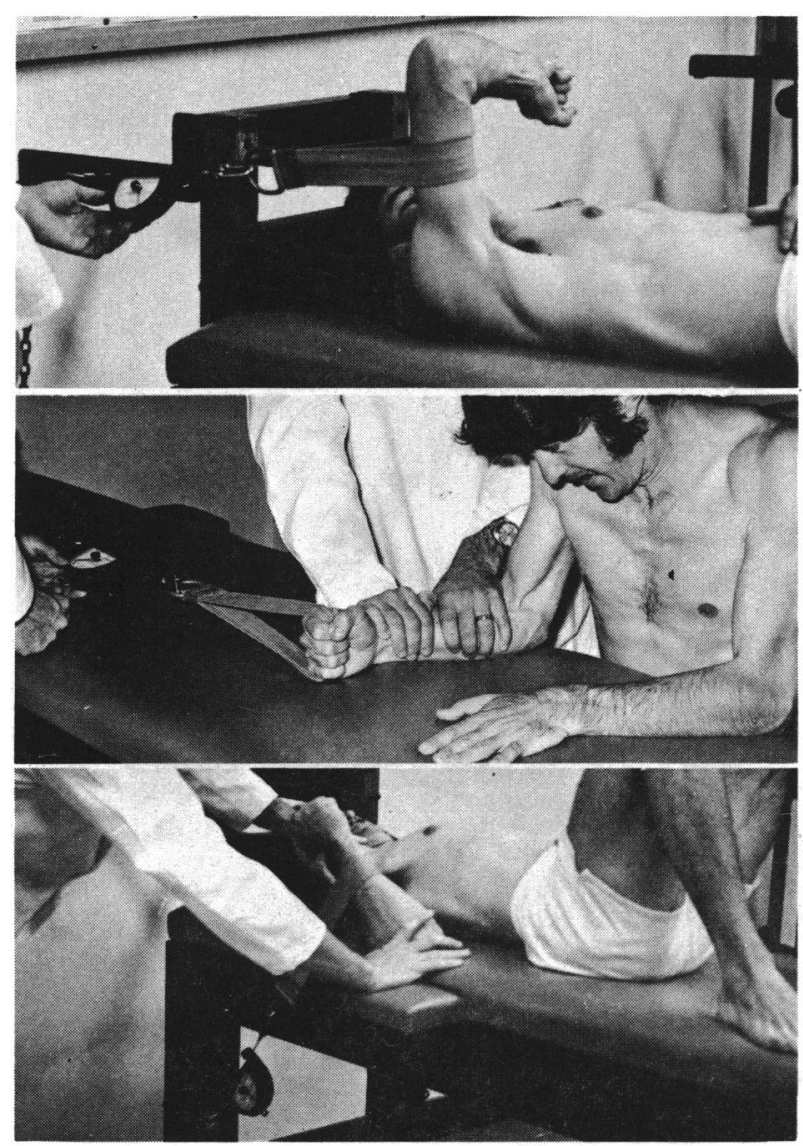

Fig. 3 Cable tension strength measurements for shoulder extension, wrist flexion and elbow extension

used to screen out extremely weak individuals. High scores on the strength tests were not necessarily considered advantageous in power stroke production.

Measurements of shoulder extension and elbow extension strength were made by using the cable tension technique described by Clarke (1953) and illustrated in Figure 3.

These tests were included because the muscles used in the movement referred to as shoulder extension by Clarke (primarily pectoralis major and latissimus dorsi) are important for ground stroke and volley production, while those used in elbow extension (mainly triceps) are necessary in overhead play.

The shoulder extension strength test was conducted by placing the strap midway between the acromion process of the shoulder joint and the olecranon process of the elbow joint. The angle at the shoulder joint was maintained at right angles to the direction of pull.

The elbow extension strength test was administered by placing the strap $10 \mathrm{cms}$ proximal to the ulnar styloid process and maintaining the elbow joint angle at $40^{\circ}$.

\section{Squash Performance Test Battery}

The components of the squash performance test battery are as follows:

(a) physical characteristics - height, weight, body fat

(b) stamina - $\mathrm{PWC}_{170}$ test on bicycle ergometer

(c) speed - squash speed test

(d) strength - shoulder extension and wrist palmar flexion strength.

(a) and (b) The measurement of the physical characteristics and stamina of the subjects was conducted in the same manner as described for the tennis battery.

\section{(c) Speed}

The squash speed test was administered on a squash court. The subject was timed to run a typical squash pattern while touching the racquet on a series of stationary balls mounted on stands placed at selected points on the court. He commenced the test by standing on the " $T$ " and ran a left or right court pattern according to the receipt of a red or green light signal similar to that described in the tennis speed test. The right court pattern is illustrated in Figure 4. The right handed player runs from the " $T$ " to the right forecourt and shadows a forehand drop shot (height $.61 \mathrm{~m}$ ), retreats to the left backcourt for a backhand boast (height . $31 \mathrm{~m}$ ), returns to the " $T$ " and touches the racquet on a small floor target, reaches for a backhand volley (height $1.50 \mathrm{~m}$ ) on the side wall, retreats again to the right backcourt for a forehand boast (height $.31 \mathrm{~m}$ ) and finished by touching the racquet on a switch placed at mid-court which stops the timer.

After several practice runs, each player was given six test trials, the red or green light being presented in random order. Left and right court speed was assessed by averaging the scores on the best two trials for each pattern. The reliability of the test, as determined by the method described 

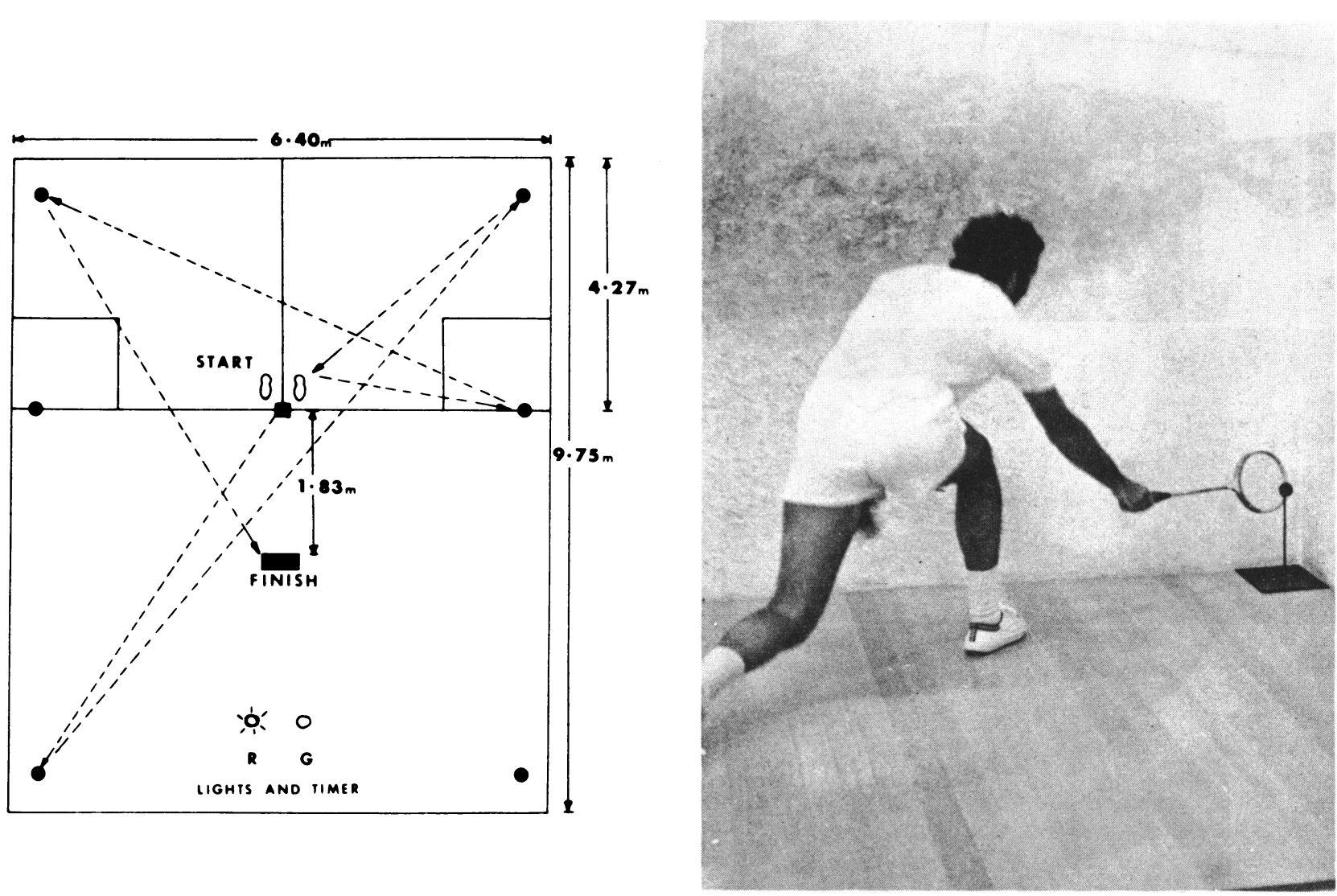

Fig. 4 Squash speed test - dimension and demonstration of simulated backhand boast.

by Baumgartner (1969), was .95. Should the more expensive timing apparatus not be available, adequate measures could be obtained by using only a stopwatch and verbal commands.

\section{(d) Strength}

The method of measurement was the same as that used with the tennis players but the wrist palmar flexion test replaced the elbow extension test. It was considered that wrist strength added to the total summation of force and played a more important role in the power stroke production of the squash player than it did for the tennis player.

In the wrist strength test, the strap was gripped in the palm of the hand and both the hand and the forearm were maintained at right angles to the direction of pull as shown in Figure 3.

\section{Test Results}

The scores obtained by the tennis and squash players on the $\mathrm{PWC}_{170}$ Test, speed runs and cable tension strength tests are presented in Table II.

Individual profiles were given to the players indicating their ranking in the group and proximity to the mean. A diagnosis based on their status on each factor measured in tennis or squash performance was then given to each player. The report filed for one of the junior girl tennis players is given below: 
Table II

Scores of Tennis and Squash Players on PWC $_{10}$ Test, Speed Runs and Cable Tension Strength Tests

STAMINA

$$
\text { PWC }_{170} \text { TEST }
$$

$\mathrm{kgm} / \mathrm{min} \quad \mathrm{kgm} / \mathrm{kg}$.
SPEED

\begin{tabular}{|c|}
\hline $\begin{array}{l}\text { Left } \\
\text { Court }\end{array}$ \\
\hline
\end{tabular}

8.02

$\pm .25$

7.41

$\pm .18$

7.36
\pm .19

$\pm 1.03$

$837.50 \quad 13.93$

$\pm 174.7 \quad \pm 3.34$

$\begin{array}{ll}8.10 & 7.93 \\ \pm .26 & \pm .29\end{array}$

8.02
\pm .28
42.5

$\pm 6.23$

57.4

$\pm 8.77$

40.7

$\pm 7.34$

27.2

$\pm 3.94$

\section{SQUASH PLAYERS}

Wrist

Palmar

Flexion

kg

$\begin{array}{llllllll}\text { Senior Men } & 1211.9 & 15.89 & 9.75 & 9.76 & 9.76 & 59.5 & 28.5 \\ (N=15) & \pm 172.7 & \pm 2.27 & \pm .43 & \pm .41 & \pm .40 & \pm 10.50 & \pm 4.42\end{array}$

Values are Means \pm S.D.

Subject A.H. - 16 years

Body Fat (\%)

Stamina

$$
(\mathrm{kgm} / \mathrm{min})
$$

(kgm/kg.min)

Speed - left court (secs)

- right court (secs)

- average (secs)

Strength

\section{Score}

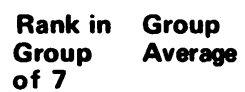

18.2

6

570

9.5

7.92

7.87

7.90

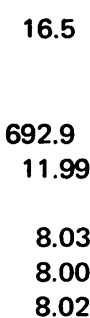

42.5

24.9

The short diagnosis for this player was; body fat, excessive; stamina, low speed, average; strength, adequate.

The report filed for one of the senior men squash players is given below:

$\begin{array}{llllc}\text { Subject R.M. - 24 years } & \text { Score } & \begin{array}{l}\text { Rank in } \\ \text { Group } \\ \text { of } 15\end{array} & \begin{array}{c}\text { Group } \\ \text { Average }\end{array} \\ \text { Body Fat (\%) } & 12.0 & 11 & 12.0 \\ \text { Stamina } & \begin{array}{l}\text { (kgm/min) } \\ \text { (kgm/kg.min) }\end{array} & 930 & 16 & 1211.9 \\ & \text { Speed } & 14.01 & 14 & 15.89 \\ & \text { - left court (secs) } & 9.53 & 6 & 9.75 \\ & \text { - right court (secs) } & 9.38 & 4 & 9.76 \\ & \text { - average (secs) } & 9.46 & 4 & 9.76 \\ \text { Strength } & & & & \\ & \begin{array}{l}\text { Shoulder extension (kg) } \\ \text { wrist flexion (kg) }\end{array} & 55.9 & 10 & 59.5 \\ & & 29.6 & 8 & 28.5\end{array}$

The short diagnosis for this player was; body fat, slightly excessive; stamina, low; speed, good; wrist strength, adequate; shoulder strength, moderate.

\section{Summary}

Tennis and squash performance test batteries were 
successfully administered to State level tennis and squash players in Western Australia. Measurements made on the tennis players included physical characteristics (height, weight and body fat), estimations of physical work capacity (stamina) at a heart rate of 170 beats/minute on a bicycle ergometer, time for a tennis speed run and strength of the muscles involved in the production of tennis strokes.

The squash players undertook the same types of tests as the tennis players but performed on a squash speed run and a wrist flexion strength test to assess elements of performance that were specific to their game.

The results of these tests were used to prescribe training programmes geared to individual needs.

\section{Acknowledgements}

Acknowledgements are extended to Mr. Tibor van Der Harst for his technical assistance throughout the study and to Mr. Gundars Tilmanis for his professional advice in devising the tennis speed test.

\section{REFERENCES}

BAUMGARTNER, T. A., Estimating Reliability When All Test Trials are Administered on the Same Day; Research Quarterly, 40, 222-225, 1969.

CANADIAN ASSOCIATION OF HEALTH, PHYSICAL EDUCATION AND RECREATION, The Physical Work Capacity of Canadian Children Aged 7 to 17, 1968.

CLARKE, H. H., Cable Tension Strength Tests; Brown-Murphy Co., Springfield, Massachusetts, 1953.

KEYS, A. and J. BROZEK, Body Fat in Adult Man; Physiological Review, 33: 245-325, 1953.

SJOSTRAND, T., Changes in Respiratory Organs of Workmen at an Ore Smelting Works; Acta Medica Scandinavica, 198: 687-699, 1947.

SLOAN, A. W., BURT, J. J., and C. S. BLYTH, Estimation of Body Fat in Young Women; Journal of Applied Physiology, 17: 967-970, 1962.

YUHASZ, M. S., The Effects of Sports Training on Body Fat in Man With Predictions of Optimal Body Weight; Unpublished Doctoral Dissertation, University of Illinois, 1962.

\section{BOOK REVIEW}

"Psychological Aspects of Physical Education and Sport"

Ed. J. E. Kane, Routledge \& Kegan Paul, pp 237, £2.50

With increasing awareness of the psychological determinants of human behaviour, it is important that attempts be made to examine these as objectively as possible.

This book presents the relevant research to date with adequate provision for further reading supplied by the comprehensive bibliographies.

This has been well done, but largely in academic format which makes it rather heavy going in places and suitable mainly for postgraduate students or those with a fairly sophisticated knowledge of physical education and psychological theories and procedures.

The presentation emphasizes the discrepancy which exists between theory as prepounded in research material and its practical application. Chapters 6 and 8 are very commendable in attempting to minimize this discrepancy. The clarity of this discussion of theoretical propositions with reference to their practical implications, make them well worth reading and of particular interest to coaches or others directly involved with those engaged in athletic or sporting activities. 